\title{
Synthesis and characterization of oxygen doped ZnTe for powder phosphor application
}

\author{
Z.T. Kang, H. Menkara, B.K. Wagner, and C.J. Summers ${ }^{\text {a) }}$ \\ Phosphor Technology Center of Excellence, School of Materials Science and Engineering, \\ Georgia Institute of Technology, Atlanta, Georgia 30332-0245 \\ V. Valdna \\ Tallinn Technical University, 19086 Tallinn, Estonia
}

(Received 22 December 2004; accepted 31 May 2005)

\begin{abstract}
The synthesis of efficient ZnTe powder phosphors is very difficult due to its high moisture sensitivity and chemical instability during processing. In this study, an efficient ZnTe:O powder phosphor for x-ray imaging application was successfully synthesized by vacuum firing ZnTe powder prepared from ZnTe bulk crystals ball-milled in an $\mathrm{O}_{2}$ atmosphere. The phosphors were characterized by x-ray diffraction, $\mathrm{x}$-ray photoelectron spectroscopy, photoluminescence, and cathodoluminescence (CL) measurements and found to exhibit a luminescent efficiency three times that of $\mathrm{ZnTe}: \mathrm{O}$ prepared by $\mathrm{ZnO}$ doping. The $\mathrm{ZnTe}: \mathrm{O}$ samples exhibited a deep red emission centered at $680 \mathrm{~nm}$ and a CL decay time of $1.1 \mu \mathrm{s}$.
\end{abstract}

\section{INTRODUCTION}

As one of the most efficient and versatile phosphors, with application in cathode ray tubes and electroluminescent devices, doped $\mathrm{ZnS}$ has been widely used for many years to produce blue to red light. Intense green and red luminescence has also been achieved in doped $\mathrm{ZnSe}{ }^{1}$ $\mathrm{ZnSe}: \mathrm{Cu}, \mathrm{Cl}$ is a red emitting $(650 \mathrm{~nm})$ scintillator with the highest known $\mathrm{x}$-ray conversion efficiency. However, $\mathrm{ZnSe}$ is not suitable for multi-wavelength anomalous dispersion (MAD) studies because the atomic absorption edge of the $\mathrm{Se}$ atom interferes with some biological cells. As the counterpart of $\mathrm{ZnS}$ and $\mathrm{ZnSe}$, ZnTe can avoid this problem and can potentially achieve efficiencies comparable to $\mathrm{ZnSe} .^{2}$ The objective of this research is to synthesize ZnTe powder phosphor materials that can be screened for large-area $(20 \times 20 \mathrm{~cm}) \mathrm{x}$-ray imaging screens and match the spectral sensitivity of convenional red sensitive charge coupled device (CCD) detectors, which has a quantum efficiency that peaks near $\sim 700 \mathrm{~nm}$.

However, unlike ZnS and ZnSe, high-efficiency ZnTe phosphors are very difficult to synthesize in powder form, probably due to their high moisture sensitivity and chemical instability during synthesis. Thus, most of the recent research on ZnTe has been focused on the synthesis of pure or doped ZnTe films for electro-optic appli-

\footnotetext{
a) Address all correspondence to this author.

e-mail: chris.summers@mse.gatech.edu

DOI: $10.1557 / J M R .2005 .0299$
}

cations. Bulk ZnTe crystals can be synthesized by meltor vapor-phase techniques. ${ }^{3-6}$ Also, ZnTe thin films have been fabricated by epitaxial growth techniques. ${ }^{7-10}$ However, little work has been reported on the synthesis of efficient luminescent ZnTe for powder phosphor applications. The photoluminescence of doped ZnTe has been widely reported, ${ }^{3,4,8-18}$ with effective dopants including oxygen,,${ }^{3,11-17}$ copper, ${ }^{4,18}$ ytterbium, ${ }^{9}$ arsenic, ${ }^{10}$ etc. However, no emission of suitable intensity and spectral properties for phosphor applications was reported. In 1962, Dietz et al. reported a broad red emission centered at $\sim 660 \mathrm{~nm}$ from vapor-grown ZnTe bulk crystals measured at $20 \mathrm{~K} .{ }^{11}$ From additional investigations on meltgrown $5 \mathrm{~mol} \% \mathrm{ZnO}$-doped ZnTe bulk crystals, this emission was attributed to an isoelectronic oxygen trap by Hopfiled et al. ${ }^{12}$ The origins and properties of this emission have been investigated further and attributed to the recombination of excitons bound to isoelectronic oxygen centers. ${ }^{3,12-17}$

In this paper, we report on the preparation of efficient ZnTe powder phosphors doped with oxygen and characterized by structural and optical measurements. To avoid reaction with water and moisture and to achieve pure substitution of oxygen at tellurium sites, oxygen was incorporated by using two different forms of a dry doping process: (i) an admixture of $\mathrm{ZnTe}$ and $\mathrm{ZnO}$ and (ii) the ball-milling of bulk ZnTe crystals into small particles in an $\mathrm{O}_{2}$ atmosphere. For comparison, $\mathrm{Cu}$ was also used to activate $\mathrm{ZnTe}$ by a regular wet doping process, since $\mathrm{Cu}$ is a very effective dopant for $\mathrm{ZnS}$ and $\mathrm{ZnSe}$. 


\section{EXPERIMENTAL}

\section{A. Synthesis}

For the synthesis, bulk ZnTe crystals of $99.999 \%$ purity were used as the raw host material and $\mathrm{ZnO}$ particles of $99.99 \%$ purity were used for oxygen doping. Ultrahigh-purity $\mathrm{O}_{2}(99.994 \%)$ and/or $\mathrm{N}_{2}(99.999 \%)$ gas was used as the ball-milling atmosphere. $\mathrm{CuCl}_{2}$ and $\mathrm{ZnCl}_{2}$ of 99.999\% purity were dissolved into de-ionized water for wet doping.

The samples under study were classified into four groups: an undoped ZnTe reference sample, two oxygendoped samples, and another $\mathrm{Cu}$-doped sample. The methods of preparation were thus: (i) $\mathrm{ZnTe}$ powders with particle size of 10-50 $\mu \mathrm{m}$, which were produced by ballmilling bulk crystals in $\mathrm{N}_{2}$ atmosphere for $48 \mathrm{~h}$ (S1); (ii) ZnTe powder ball-milled from bulk crystals in $\mathrm{O}_{2}$ atmosphere for $48 \mathrm{~h}$ (S2); (iii) dry mixtures of $\mathrm{ZnTe}-\mathrm{ZnO}(\mathrm{S} 3)$ prepared at concentrations of $[\mathrm{ZnO}]=$ 0.2 , 1, and $5 \mathrm{wt} \%$ (ZnTe powder is from $\mathrm{S} 1$ ); and (iv) $\mathrm{ZnTe}: \mathrm{Cu}, \mathrm{Cl}$ (S4) formed by wet doping with $\mathrm{CuCl}_{2}$ and a $2 \mathrm{wt} \% \mathrm{ZnCl}_{2}$ solution into $\mathrm{ZnTe}$ powder obtained from $\mathrm{S} 1$, at concentrations of $\left[\mathrm{Cu}^{+}\right]=0.01$ to 0.1 at\%. Thus, as shown in Table I, samples S2 and S3 were dry-doped ZnTe:O, sample S4 was wet doped $\mathrm{ZnTe}: \mathrm{Cu}, \mathrm{Cl}$, and sample $\mathrm{S} 1$ was undoped.

After being dried and evacuated to $10^{-2}$ to $10^{-3}$ Torr in a quartz tube, all the samples were fired in the quartz tubes at $1000{ }^{\circ} \mathrm{C}$ in vacuum for $1 \mathrm{~h}$, and then the tube was quenched in air. The S4 samples were synthesized according to the regular procedures used for $\mathrm{ZnS}$ and $\mathrm{ZnSe}$ phosphor synthesis. ${ }^{19}$ Efficient $\mathrm{ZnSe}$ powder phosphors have been previously synthesized in our laboratory using the same procedures.

\section{B. Characterization}

Physical characterization was performed to analyze the bulk phase purity and the surface chemical properties. For the phase purity studies, the samples were analyzed by x-ray diffraction (XRD) on a Phillips PW-1800 x-ray diffractometer with $\mathrm{Cu} \mathrm{K}_{\alpha}(\lambda=0.15405 \mathrm{~nm})$ radiation (40 kV, 30mA). Surface chemical analysis was performed by x-ray photoelectron spectroscopy (XPS) with a Surface Science model SSX-100 Small Spot ESCA system using the $\mathrm{Al} \mathrm{K}_{\alpha}$ line $(1486.6 \mathrm{eV})$. The photoluminescence (PL) intensities of the samples were compared using an OceanOptics USB2000 (Dunedin, FL)

TABLE I. Sample conditions and doping methods.

\begin{tabular}{lllc}
\hline \hline No. & \multicolumn{1}{c}{ Crystal } & \multicolumn{1}{c}{ Dopants } & $\begin{array}{c}\text { Doping } \\
\text { method }\end{array}$ \\
\hline S1 & $\mathrm{ZnTe}$ & \multicolumn{1}{c}{$\ldots$} & $\ldots$ \\
S2 & $\mathrm{ZnTe}: \mathrm{O}$ & $\mathrm{O}_{2}$ & dry \\
S3 & $\mathrm{ZnTe}: \mathrm{O}$ & $\mathrm{ZnO}$ & dry \\
S4 & $\mathrm{ZnTe}: \mathrm{Cu}, \mathrm{Cl}$ & $\mathrm{CuCl}_{2}, \mathrm{ZnCl}_{2}$ & wet \\
\hline \hline
\end{tabular}

spectrometer connected to an integrating sphere equipped with a $470 \mathrm{~nm}$ blue LED as the exciting source. The photoluminescent excitation spectra (PLE) and also some of the PL spectra were obtained with a Spex1000M spectrometer (Edison, NJ) using a $150 \mathrm{~W}$ xenon lamp/ monochromator combination as the excitation source. The cathodoluminescent (CL) emission spectra were direct-current (dc) excited at various energies up to $20 \mathrm{keV}$ at a low current density of $\sim 5 \mu \mathrm{A} / \mathrm{cm}^{2}$, using a custom Kimball Physics EFG-11 electron gun (Wilton, NH) as the excitation source. All the CL measurements were performed at room temperature and recorded with a SpectraScan PR705 spectrophotometer (Kempston, UK). Pulsed CL measurements were also performed to investigate the time-resolved luminescence properties.

\section{RESULTS AND DISCUSSION}

\section{A. Effect of doping method on phase purity}

The experimental results showed that the doping method had a strong effect on the phase purity and luminescence properties of the $\mathrm{ZnTe}$ phosphor. Both $\mathrm{ZnO}$ and Te impurity phases were detected from almost all of the wet doped $\mathrm{ZnTe}: \mathrm{Cu}, \mathrm{Cl}$ samples (S4) after they had been fired at $1000{ }^{\circ} \mathrm{C}$. The XRD spectrum of a typical S4 sample is shown in Fig. 1(a); the intense diffraction peaks at $36.8^{\circ}$ and $28.1^{\circ}$, respectively, indicate a large proportion of a hexagonal $\mathrm{ZnO}$ phase and a hexagonal Te phase are present in the sample. These phases are believed to be the reaction products of $\mathrm{ZnTe}$ with $\mathrm{H}_{2} \mathrm{O}$ during the long term mixing, drying, and firing procedures and are attributed to the moisture sensitivity and chemical instability of $\mathrm{ZnTe}$. Absorbed water in $\mathrm{ZnTe}$ is very difficult to fully remove from the wet-doped samples and is very reactive during the following hightemperature firing process. In contrast, a pure ZnTe phase was obtained from the dry-doped ZnTe:O samples (S2) synthesized by ball-milling in $\mathrm{O}_{2}$. As shown in

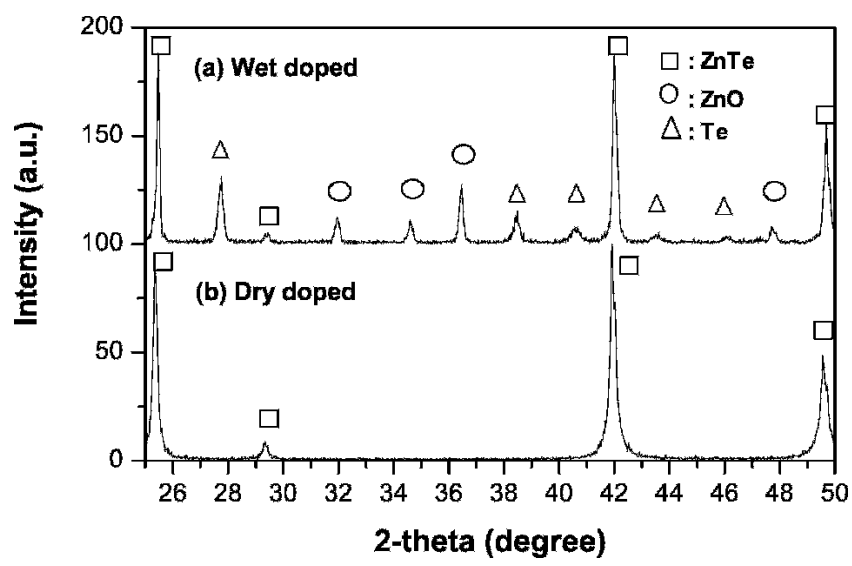

FIG. 1. XRD patterns of ZnTe samples fired at $1000{ }^{\circ} \mathrm{C}$ : (a) wetdoped $\mathrm{ZnTe}: \mathrm{Cu}, \mathrm{Cl}(\mathrm{S} 4)$ and (b) dry-doped $\mathrm{ZnTe}: \mathrm{O}$ (S2) prepared by ball-milling in $\mathrm{O}_{2}$. 
Fig. 1(b), only diffraction peaks at $25.5^{\circ}, 42.0^{\circ}, 49.8^{\circ}$, and $29.2^{\circ}$ were observed, which are respectively from the (111), (220), (311), and (200) planes of a cubic ZnTe phase, confirming that a pure ZnTe phase was achieved. The XRD spectra of the dry-doped S3 samples (which are not shown in Fig. 1) also indicated that only a pure $\mathrm{ZnTe}$ phase was detected after firing at $1000{ }^{\circ} \mathrm{C}$. This was directly attributed to the fact that no water was introduced into the raw materials during the dry synthesis process. Thus, any reaction with $\mathrm{H}_{2} \mathrm{O}$ was avoided or greatly reduced.

A reaction between the wet-doped samples and quartz was also observed by the formation of a white dendritic layer on the wall of the quartz tube. A similar deposit was also observed by Valdna et al. ${ }^{19}$ when they fired wetdoped $\mathrm{ZnTe}$ or $\mathrm{ZnSe}_{1-x} \mathrm{Te}_{x}$ solid solution powders in quartz ampoules. From x-ray microanalysis measurements, they identified this layer to be $\mathrm{SiO}_{x}-\mathrm{ZnO}_{x}$. In contrast, for the undoped $\mathrm{ZnTe}$, no reaction was observed between the sample and the quartz tube during the firing process. Also, for the dry doped S2 and S3 samples, the reaction between $\mathrm{ZnTe}$ and the quartz ampoule was greatly reduced, thus giving further confirmation that this reaction was related to the presence of absorbed water on the raw starting materials.

\section{B. Surface chemical state}

After synthesis, the samples exhibited different body colors. The undoped S1 samples exhibited a deep red color, whereas the dry oxygen doped S2 and S3 samples were brown in appearance. For the $\mathrm{S} 3$ samples, the color became deeper with increased $\mathrm{ZnO}$ additions. To understand this change in body color, the chemical state of surface was analyzed by XPS, as shown in Fig. 2. For $\mathrm{ZnTe}$, the XPS spectra of the Te $3 d$ core levels show two Te peaks, Te $3 d_{5 / 2}$, and Te $3 d_{3 / 2}$, at energies of 573.5 and $584 \mathrm{eV}$, respectively. ${ }^{20}$ These peaks are accompanied by two peaks at 577 and $587.5 \mathrm{eV}$, which are identified as being due to the emission from the $3 d$ core levels of Te in an oxide environment. Thus, Fig. 2(a) indicates that tellurium oxide was formed on the surface of $\mathrm{O}_{2}$-doped $\mathrm{ZnTe}$, while undoped $\mathrm{ZnTe}$ showed no oxidation because the tellurium oxide peaks were not detected. As shown in Fig. 2(b), for $\mathrm{ZnO}$-doped $\mathrm{ZnTe}$, the tellurium oxide surface layer was much thicker than that on the $\mathrm{S} 2$ samples, as estimated from the relative intensities of the tellurium and tellurium oxides peaks. Additionally, with increasing $\mathrm{ZnO}$ concentration, the surface oxide layer thickness increases. Morris et al. ${ }^{21}$ also reported that the thin brown layer formed on the crystal surfaces is a tellurium oxide.

For the wet-doped S4 samples, the body color was much darker than that of the dry-doped ones, with some samples even looking black. The heavily oxidized surface revealed by XPS measurements and the presence of
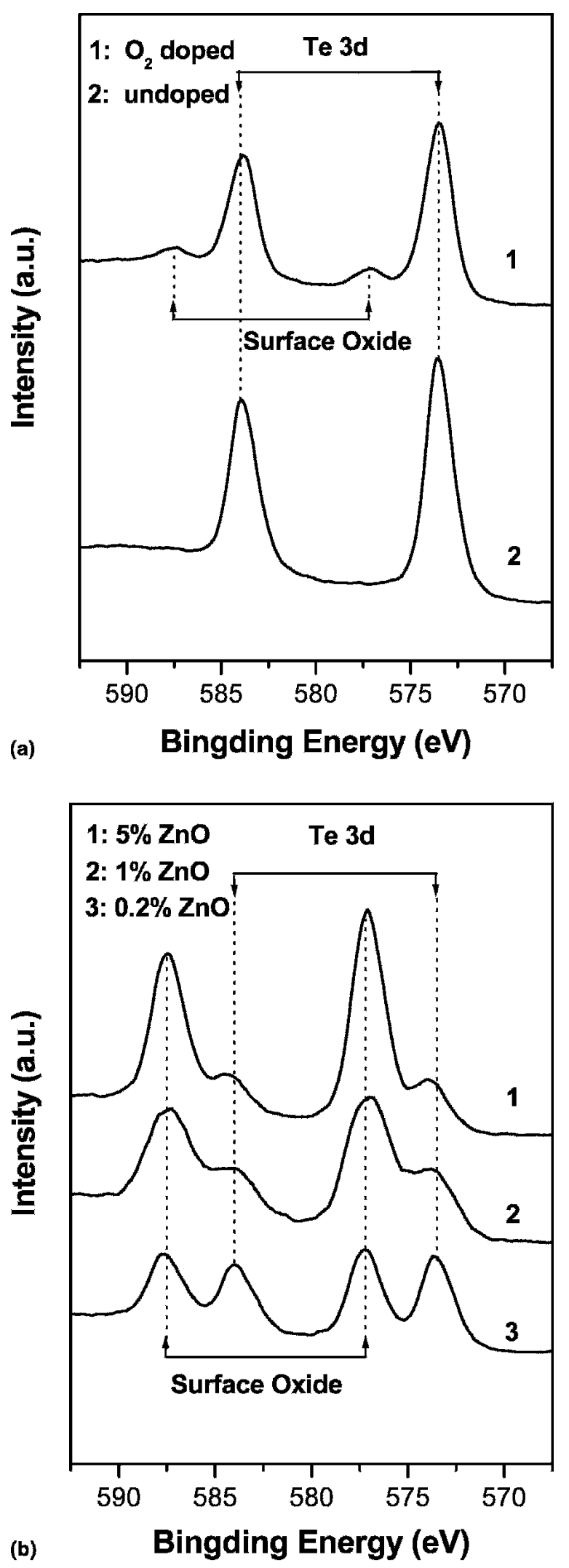

FIG. 2. XPS spectra of (a) ZnTe:O (S2) doped by ball-milling in $\mathrm{O}_{2}$ (curve 1) and undoped $\mathrm{ZnTe}$ (S1) prepared by ball-milling in $\mathrm{N}_{2}$ (curve 2), and (b) ZnTe:O (S3) samples doped with $\mathrm{ZnO}$ concentrations between $0.2 \%$ and $5 \%$. 
a pure tellurium phase in the samples may also be responsible for the dark color.

\section{Photoluminescence properties}

Under $470 \mathrm{~nm}$ excitation, both the undoped $\mathrm{ZnTe}(\mathrm{S} 1)$ and the wet-doped $\mathrm{ZnTe}: \mathrm{Cu}, \mathrm{Cl}$ samples exhibited no PL at room temperature, while a broad red emission centered at $\sim 680 \mathrm{~nm}$ was observed from the oxygen doped S2 and $\mathrm{S} 3$, as shown in Fig. 3. This luminescence band is attributed to the emission from an exciton bound to an isoelectronic oxygen, which forms a deep electron trap in ZnTe. ${ }^{3,11-17}$ It was also observed that the S2 samples doped by ball-milling in $\mathrm{O}_{2}$ exhibited a much higher PL intensity than the $\mathrm{S} 3$ samples doped by $\mathrm{ZnO}$ addition. And with increasing $\mathrm{ZnO}$ doping concentration, from $0.2 \%$ to $5 \%$, the PL intensity decreased. The PL emission intensities from the $0.2 \%, 1 \%$, and $5 \% \mathrm{ZnO}$-doped samples were about $27 \%, 20 \%$, and $9 \%$ that of the typical $\mathrm{O}_{2}$ doped sample, respectively.

From previous studies Valdna et al. have identified two possible mechanisms that can reduce the PL intensity in tellurides, which do not exist or which are negligible in the sulfides and selenides: ${ }^{19}$ (i) a tellurium oxide layer is formed on the crystal surface and (ii) an interstitial tellurium or a complex defect formed with $\mathrm{Te}_{\mathrm{i}}$. Interstitial Te is probably the PL killer in the tellurides and is precipitated when an excess of tellurium is formed during the thermal treatment. Therefore, the absence of luminescence from the wet-doped S4 samples could be attributed to both the heavily oxidized surface structure and the presence of an excess tellurium impurity phase after firing. For the $\mathrm{ZnO}$-doped $\mathrm{S} 3$ samples, the luminescence intensity decreased with increasing $\mathrm{ZnO}$ concentration, which could also be attributed to the increase in the surface tellurium oxide layer thickness, as indicated by XPS results.

As was reported for $\mathrm{ZnSe}: \mathrm{O}$ and $\mathrm{ZnSe}_{1-x} \mathrm{Te}_{x}: \mathrm{O}$ formed

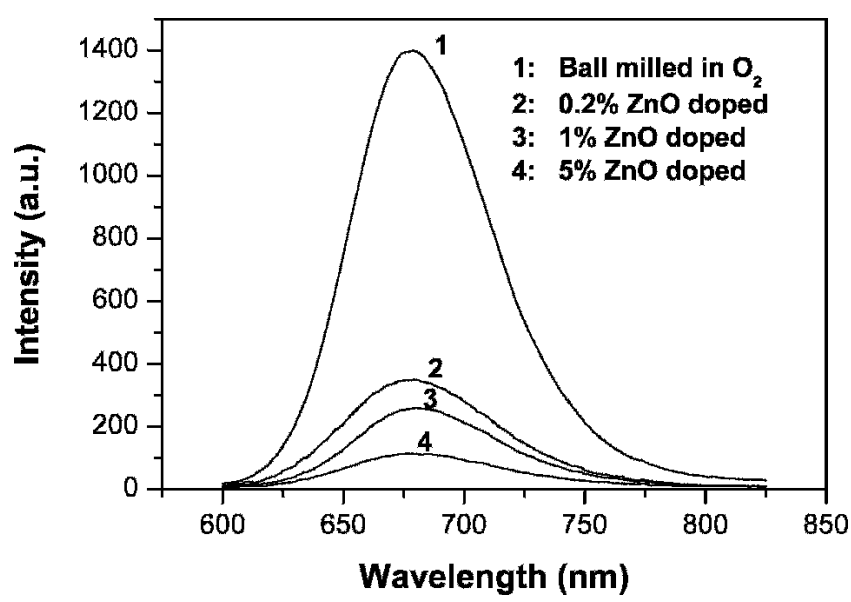

FIG. 3. PL spectra of $\mathrm{ZnTe}: \mathrm{O}$ doped by $\mathrm{O}_{2}$ or $\mathrm{ZnO}$ (470 nm excitation at room temperature). by grinding bulk crystals in an $\mathrm{O}_{2}$ atmosphere, the ballmilling of ZnTe crystals in an $\mathrm{O}_{2}$ atmosphere mechanically stimulates ion implantation of active forms of oxygen $\left(\mathrm{O}^{\prime}, \mathrm{O}_{2}{ }^{\prime}, \mathrm{O}^{x}\right.$, etc.) into the lattice due to large local electric fields in the region of microcracks formed during crystal destruction. ${ }^{22}$ Thus, a high concentration of oxygen related centers can be incorporated and uniformly distributed in the crystals, leading to the efficient luminescence of $\mathrm{S} 2$ samples. It is also interesting to note that the $\mathrm{O}_{2}$ atmosphere ball-milling of ZnTe powders, which had already been thoroughly ground into small particles, did not lead to oxygen induced luminescence. This is because ion implantation emulation cannot be achieved without the creation of microcracks in the powder. In contrast, in a $\mathrm{ZnTe}-\mathrm{ZnO}$ admixture the $\mathrm{ZnO}$ particles are likely bonded onto the ZnTe surface and have a lower solubility and diffusion rate in the ZnTe crystal during the firing process. Thus, a uniform distribution of oxygen is difficult to achieve by firing dry mixed $\mathrm{ZnTe}$ and $\mathrm{ZnO}$ particles, and the addition of $\mathrm{ZnO}$ is not an efficient way to dope ZnTe. In addition, a thicker tellurium oxide surface layer was observed in the S3 samples, which would also result in a lower luminescent efficiency.

Figure 4 shows the typical PL and PLE spectra of ZnTe:O samples prepared by ball-milling in $\mathrm{O}_{2}$. The PL spectrum was measured at room temperature using $470 \mathrm{~nm}$ excitation. The main emission peak is centered at $685 \mathrm{~nm}$ with a half maximum width of $\sim 73 \mathrm{~nm}$, as reported for isoelectronic oxygen centers in ZnTe., ${ }^{3,12-17}$ Two very weak peaks located at 577 and $579 \mathrm{~nm}$ were also observed, as shown in the inset of Fig. 4. For the PLE spectra, the investigated excitation wavelength was from 450 to $640 \mathrm{~nm}$. The excitation spectrum consists of two strong excitation bands, a broad band centered at $606 \mathrm{~nm}$ on which is imposed a sharp peak centered at $553 \mathrm{~nm}$. The broad band is due to the absorption of

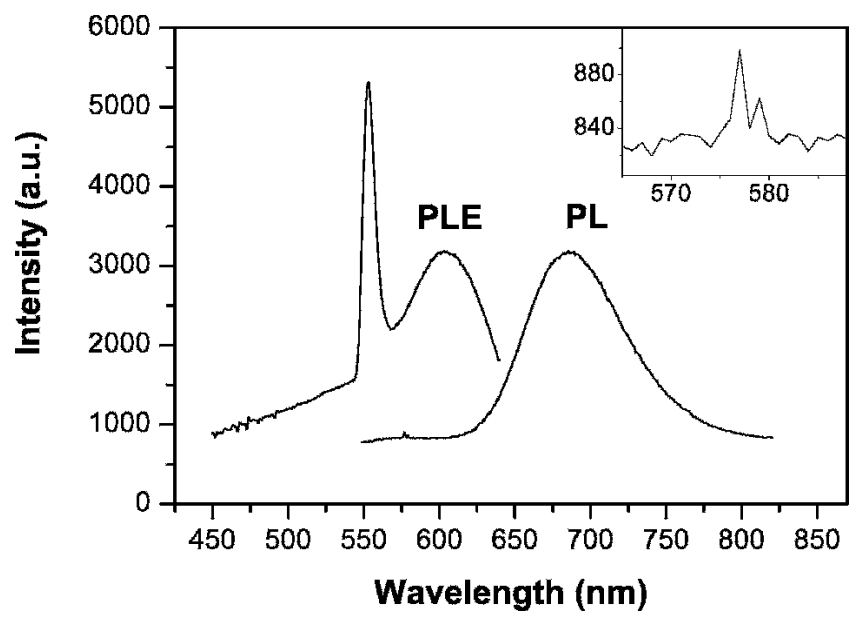

FIG. 4. PL and PLE spectra of a typical ZnTe:O sample doped by ball-milling in $\mathrm{O}_{2}$ (inset shows the near band edge PL emission; the PL was measured at room temperature with $470 \mathrm{~nm}$ excitation.). 
oxygen centers, which is very symmetrical to the emission band. ${ }^{11}$ The sharp band extends between 545 and $570 \mathrm{~nm}$. Iida has reported similar PLE results for ZnTe:O at $77 \mathrm{~K},{ }^{15}$ but no interpretation of the origin of this sharp excitation band was given.

The band gap of pure ZnTe at $300 \mathrm{~K}$ is $2.25 \mathrm{eV}$ $(552 \mathrm{~nm})$. Doping of oxygen in $\mathrm{ZnTe}$ could cause a small shift of the band gap. The $553 \mathrm{~nm}$ excitation band is possibly attributed to the band edge absorption, although it seems too sharp to be a band edge absorption. The 577 and $579 \mathrm{~nm}$ emission might be caused by shallow donor-acceptor pairs or free to bound transitions. Further experiments are needed to identify the origin of this excitation band.

\section{Cathodoluminescence properties}

Figure 5(a) shows the CL spectra of ZnTe samples when excited by $20 \mathrm{keV}$ electrons. A broad emission centered at $\sim 684 \mathrm{~nm}$ was also observed both from the $\mathrm{O}_{2}$ doped and $0.2 \% \mathrm{ZnO}$ doped samples. The CL efficiency of the $\mathrm{O}_{2}$-doped sample was more than 3 times higher

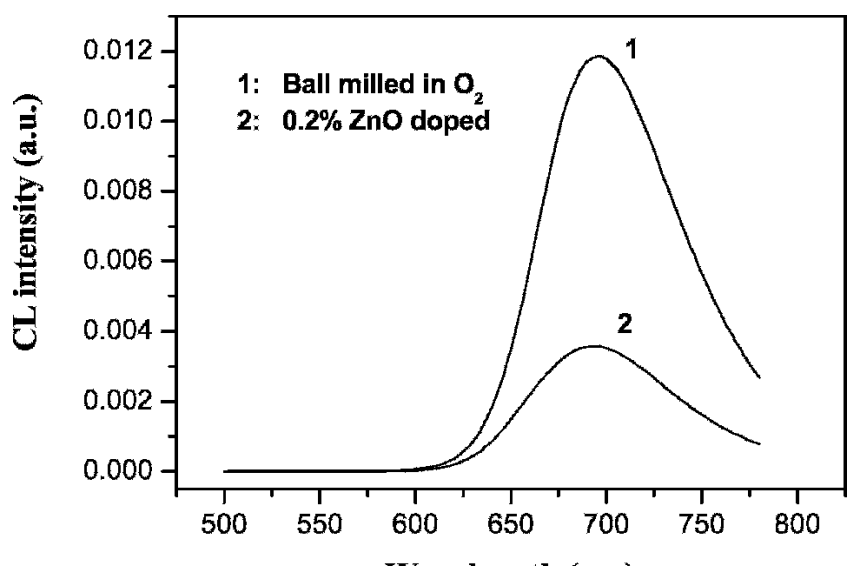

(a)

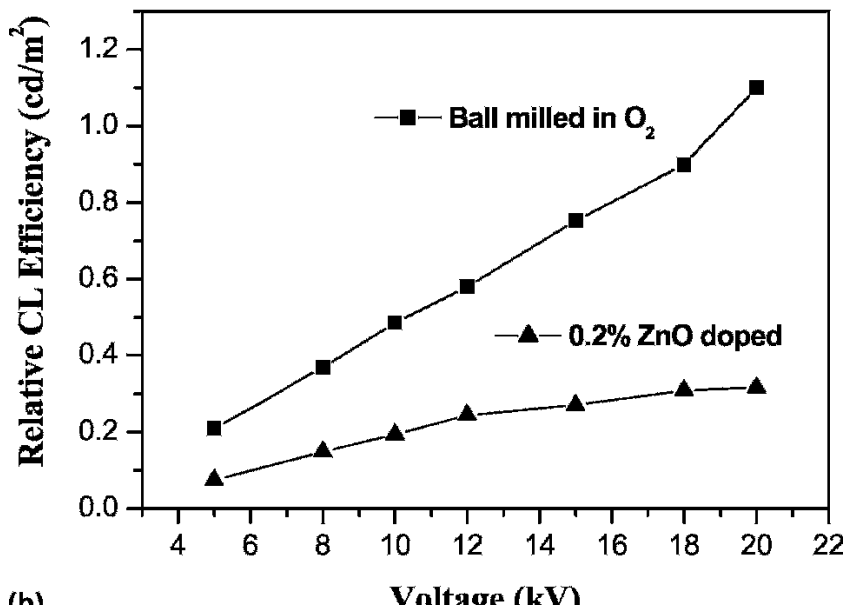

(b)

Voltage (kV)

FIG. 5. (a) CL spectra of $\mathrm{ZnTe}: \mathrm{O}$ doped by $\mathrm{O}_{2}$ or $\mathrm{ZnO}$ and (b) $\mathrm{CL}$ efficiency of ZnTe:O in (a). than the $0.2 \% \mathrm{ZnO}$-doped sample. The relative CL efficiencies of $\mathrm{O}_{2}$-doped and $0.2 \% \mathrm{ZnO}$-doped $\mathrm{ZnTe}$ samples as a function of electron energy are shown in Fig. 5(b). Both samples showed no saturation at high voltages, which may indicate a long diffusion length of electron-hole pairs. The $\mathrm{CL}$ efficiency for $\mathrm{ZnO}$-doped samples increases at a relatively slower rate with increasing voltage compared to the $\mathrm{O}_{2}$-doped sample, and the slope decreases at higher voltages. This may be due to the decreasing oxygen concentration with depth because of the slower diffusion rate of $\mathrm{ZnO}$ in $\mathrm{ZnTe}$.

Compared to the CL efficiency of commercial $\mathrm{ZnS}: \mathrm{Cu}, \mathrm{Cl}$ phosphor, the CL efficiency of synthesized $\mathrm{ZnTe}: \mathrm{O}$ is low, $\sim 1 \%$ of $\mathrm{ZnS}: \mathrm{Cu}, \mathrm{Cl}$. However, for $\mathrm{x}$-ray phosphor applications, due to the lower bandgap, and higher x-ray absorption efficiency of ZnTe, the x-ray conversion efficiency of ZnTe phosphors can potentially be comparable to $\mathrm{ZnSe}$ and $\mathrm{ZnS}$ phosphors. ${ }^{2}$ Recent $\mathrm{x}$ ray luminescence results of the $\mathrm{ZnTe}: \mathrm{O}$ phosphors, which will be reported elsewhere, ${ }^{23}$ exhibited an efficiency of up to $56 \%$ of the most efficient $\mathrm{ZnSe}: \mathrm{Cu}, \mathrm{Cl}$ phosphors.

Figure 6 shows the CL decay curve of ZnTe:O doped by ball milling in $\mathrm{O}_{2}$. It is seen that the luminescence exhibits an exponential decay, and no afterglow was observed from the sample. The phosphor shows a very fast decay with 1/e decay time of about $1.1 \mu \mathrm{s}$. This result is close to the value measured by Cuthbert et al. ${ }^{17}$ on bulk $\mathrm{ZnTe}: \mathrm{O}$ crystals at the wavelength of peak emission intensity.

\section{CONCLUSIONS}

ZnTe:O powder phosphors were successfully prepared by vacuum firing $\mathrm{ZnTe}$ powder ball-milled in $\mathrm{O}_{2}$ atmosphere from bulk crystals. It is very difficult to synthesize ZnTe powder phosphor by a wet-doping process because

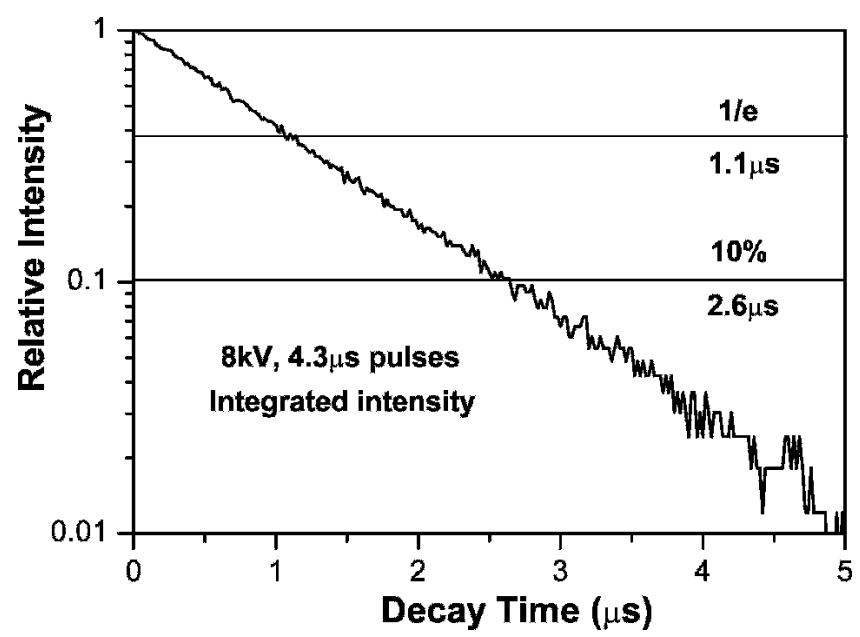

FIG. 6. $8 \mathrm{kV}$ CL decay curve of $\mathrm{ZnTe}: \mathrm{O}$ doped by ball milling in $\mathrm{O}_{2}$. 
a pure phase usually cannot be obtained due to the reaction of ZnTe with $\mathrm{H}_{2} \mathrm{O}$. Dry doping by $\mathrm{O}_{2}$ through ballmilling is an effective way to synthesize $\mathrm{ZnTe}$ :O powder phosphors with a strong red emission centered at $680 \mathrm{~nm}$ and a decay time of $1.1 \mu \mathrm{s}$. Two excitation bands centered at 553 and $606 \mathrm{~nm}$, respectively, were observed to be responsible for this red emission. The emission intensity of $\mathrm{O}_{2}$-doped samples was found to be more than three times as efficient as for the $\mathrm{ZnO}$-doped samples due to a more uniform distribution of oxygen substitutional doping on tellurium sites.

\section{ACKNOWLEDGMENTS}

The authors would like to thank Dr. Brent Carter for the assistance with the XPS measurements. We also thank Dr. R. Durst, Dr. Y. Diawara, and Dr. E. Westbrook for their interest in this work and many discussions. This research was financially supported by the Molecular Beam Consortium.

\section{REFERENCES}

1. G.B. Stringfellow and R.H. Bube: Photoelectronic properties of ZnSe crystals. Phys. Rev. 171, 903 (1968).

2. R. Durst, Y. Diawara, G. Mednikova, T. Thorson, V. Valdna, and C. Summers: Advances in x-ray scintillator technology, 13th ESRF Users Meeting, Grenoble, France, 2003.

3. M.J. Seong, I. Miotkowski, and A.K. Ramdas: Oxygen isoelectronic impurities in ZnTe: Photoluminescence and absorption spectroscopy. Phys. Rev. B 58, 7734 (1998).

4. Y. Biao, M. Azoulay, M.A. George, A. Burger, W.E. Collins, E. Silberman, C.H. Su, M.E. Volz, F.R. Szofran, and D.C. Gillies: Photoluminescence of vapor and solution grown $\mathrm{ZnTe}$ single crystals. J. Cryst. Growth 138, 219 (1994).

5. J.A. Garcia, A. Remon, V. Munoz, and R. Triboulet: Photoluminescence study of radiative transitions in ZnTe bulk crystals. J. Cryst. Growth 191, 685 (1998).

6. T. Taguchi, S. Fujita, and Y. Inuishi: Growth of high-purity ZnTe single crystals by the sublimation travelling heater method. J. Cryst. Growth 45, 204 (1978).

7. R. Widmer, D.P. Bortfeld, and H.P. Kleinknecht: Liquid phase epitaxy on zinc telluride. J. Cryst. Growth 6, 237 (1970).

8. V.S. Bagaev, V.V. Zaitsev, and E.E. Onishchenko: Luminescence of ZnTe films caused by two types of isovalent substitution. Phys. Solid State 38, 953 (1996).

9. N.N. Loiko, V.M. Konnov, Y.G. Sadofyev, E.I. Makhov, A.S. Trushin, and A.A. Gippius: Photoluminescence of $\mathrm{Yb}$ doped ZnTe. Phys. Status Solidi 229, 317 (2002).

10. K. Hayashida, T. Tanaka, M. Nishio, Y. Chang, J. Wang, S. Wang, Q. Guo, and H. Ogawa: Photoluminescence spectra of arsenic-doped ZnTe films grown by metalorganic vapor-phase epitaxy (MOVPE) using triethylarsine. J. Cryst. Growth 237-239, 1580 (2002).

11. R.E. Dietz, D.G. Thomas, and J.J. Hopfield: "Mirror" absorption and fluorescence in ZnTe. Phys. Rev. Lett. 8, 391 (1962).

12. J.J. Hopfield, D.G. Thomas, and R.T. Lynch: Isoelectronic donors and acceptors. Phys. Rev. Lett. 17, 312 (1966).

13. Y. Burki, W. Czaja, V. Capozzi, and P. Schwendimann: The temperature dependence of the photoluminescence and lifetime of ZnTe:O. J. Phys. Condens. Mater. 5, 9235 (1993).

14. C.B. Norris: Temperature, injection level, and frequency dependences of some extrinsic luminescence bands in ZnTe. J. Electron. Mater. 8, 733 (1979).

15. S. Iida: Luminescence due to oxygen and self-activated centers in zinc telluride. J. Phys. Soc. Jpn. 32, 142 (1972).

16. C.B. Norris and H.P. Hjalmarson: The effects of Zn-vapor or Te-vapor heat treatment on the luminescence of ZnTe. J. Electron. Mater. 15, 331 (1986).

17. J.D. Cuthbert and D.G. Thomas: Fluorescent decay times of excitions bound to isoelectronic traps in GaP and ZnTe. Phys. Rev. 154, 763 (1967).

18. N. Magnea, E. Molva, and D. Bensahel: Pair spectra in copperdoped zinc-telluride. Phys. Rev. B 22, 2983 (1980).

19. V. Valdna, J. Hiie, U. Kallavus, A. Mere, and T. Piibe: $\mathrm{ZnSe}_{1-x} \mathrm{Te}_{x}$ solid solutions. J. Cryst. Growth 161, 177 (1996).

20. M.A. Foad, M. Watt, A.P. Smart, C.M.S. Torres, C.D.W. Wiikinsont, W. Kuhns, H.P. Wagner, S. Bauers, H. Leiderers, and W. Gebhardts: High-resolution dry etching of zinc telluride: characterization of etched surfaces by $\mathrm{x}$-ray photoelectron spectroscopy, photoluminescence and Raman scattering. Semicond. Sci. Technol. 6, All5 (1991).

21. G.C. Morris and P.G. Tanner: Preparation and properties of undoped and copper doped zinc telluride films. Mater. Forum 15, 179 (1991).

22. V.D. Ryzhikov, N.G. Starzhinskiy, L.P. Gal'chinetskii, V.I. Silin, G. Tamulaitis, and E.K. Lisetskaya: The role of oxygen in formation of radiative recombination centers in $\mathrm{ZnSe}_{1-\mathrm{x}} \mathrm{Te}_{x}$ crystals. Inter. J. Inorg. Mater. 3, 1227 (2001).

23. Z.T. Kang, H. Menkara, B.K. Wagner, and C.J. Summers: Effects of annealing atmosphere on the luminescent efficiency of ZnTe: O phosphors. J. Lumin. (in press). 